\title{
Phenolic and non-Phenolic Fractions of the Olive Oil Mill Wastewaters as Corrosion Inhibitor for Steel in $\mathrm{HCl}$ medium
}

\author{
A. Khadiri, ${ }^{a}$ A. Ousslim, ${ }^{a}$ K. Bekkouche, ${ }^{a}$ A. Aouniti, ${ }^{b}$ \\ A. Elidrissi, ${ }^{b}$ B. Hammouti ${ }^{b, *}$ \\ ${ }^{a}$ LCSMA - Faculté des Sciences, Université Mohammed Premier, \\ B.P. 717, 60000 Oujda, Morocco \\ ${ }^{b}$ LCAE-URAC18, Faculté des Sciences, Université Mohammed Premier, \\ B.P. 717, 60000 Oujda, Morocco
}

Received 4 February 2014; accepted 26 February 2014

\begin{abstract}
The inhibition of the corrosion of Mild Steel (MS) in $1 \mathrm{M} \mathrm{HCl}$ solution by a new synthesised organic compound, namely 1,1'-(2,2'-(2,2'-oxybis(ethane-2,1-diyl)bis (sulfanediyl))bis(ethane-2,1-diyl))diazepan-2-one, has been studied by weight loss measurements, electrochemical polarisation and electrochemical impedance spectroscopy (EIS). The experimental results have showed that this organic compound revealed a good corrosion inhibition and the inhibition efficiency is increased with the inhibitor concentration to reach $97 \%$ at $1 \mathrm{mM}$. Potentiodynamic polarisation suggested that it is a mixed type of inhibitor. EIS measurements show an increase of the polarisation resistance with the inhibitor concentration and the electrical equivalent circuit is determined. The inhibitor adsorption process on (MS) surfaces obeys the Langmuir adsorption isotherm and the adsorption isotherm parameters $\left(\mathrm{K}_{\mathrm{ads}}, \Delta \mathrm{G}_{\mathrm{ads}}\right.$, $\Delta \mathrm{H}_{\mathrm{ads}}$ and $\Delta \mathrm{S}_{\mathrm{ads}}$ ) were determined. The temperature effect on the corrosion behaviour of (MS) in $1 \mathrm{M} \mathrm{HCl}$ without and with inhibitor at different concentration was studied in the temperature range from 308 to $353 \mathrm{~K}$ and the kinetic parameters activation such as $\mathrm{E}_{\mathrm{a}}, \Delta \mathrm{H}_{\mathrm{a}}$ and $\Delta \mathrm{S}_{\mathrm{a}}$ were evaluated.
\end{abstract}

Keywords: corrosion; inhibition; thermodynamic, adsorption, azepane.

\section{Introduction}

The corrosion of steel and ferrous alloys is a fundamental process playing an important role in economies and public safety [1]. Mild Steel is a well-known material used commonly in various industries. Acid solutions are often used for the removal of rust and scale in several industrial processes. In this case,

\footnotetext{
* Corresponding author. E-mail address: hammoutib@gmail.com
} 
hydrochloric acid is one of the most widely used agents. Various types of organic compounds are widely used as corrosion inhibitors for protection of materials against deterioration from corrosion [2-14]. A persuade of the literature on acid corrosion inhibitors reveals that most organic substances employed as corrosion inhibitors act by adsorption on the metal surface. The adsorption of the inhibitors mainly depends on the presence of $\pi$-electrons and heteroatoms such as nitrogen, oxygen, phosphorus and sulphur, which are considered as adsorption centres [1517].

In this work, we investigate the corrosion of (MS) in $1 \mathrm{M} \mathrm{HCl}$ by 1,1'-(2,2'-(2,2'oxybis(ethane-2,1-diyl)bis(sulfanediyl))bis(ethane-2,1-diyl))diazepan-2-one (AZEPE). Weight loss tests and electrochemical techniques such as potentiodynamic polarisation and electrochemical impedance spectroscopy have been used to study the effect of addition of this compound on the corrosion of steel in hydrochloric acid solution.

\section{Experimental}

\section{Inhibitor}

A mixture of $\mathrm{N}$-vinyl caprolactame $(27.84 \mathrm{~g}, 0.2 \mathrm{~mol})$ and 2, 2-azo-bisisobutyronitrile $(\mathrm{AIBN})\left(0.082 \mathrm{~g}, 5 \times 10^{-4} \mathrm{~mol}\right)$ in $100 \mathrm{~mL}$ of acetonitrile $\left(\mathrm{CH}_{3} \mathrm{CN}\right)$ was added drop by drop during $30 \mathrm{~min}$ to 2-mercaptoethylether dissolved in 50 $\mathrm{mL}$ of acetonitrile. Then, the mixture was stirred during $3 \mathrm{~h}$ in the presence of pure nitrogen $\left(\mathrm{N}_{2}\right)$ at $70{ }^{\circ} \mathrm{C}$ under atmospheric pressure. The solvent and the excess of 2-mercaptoethylether were removed and the product was purified by chromatographic on a silica column (eluent $\mathrm{CH}_{2} \mathrm{Cl}_{2}$ ), to give AZEPE product as yellow oil, yield $90 \%$. A schematic representation of the synthesis is shown in Fig. 1. This inhibitor was synthesized according to A. Ousslim in our laboratory and characterised by ${ }^{1} \mathrm{H}-\mathrm{NMR},{ }^{13} \mathrm{C}-\mathrm{NMR}$ and IR spectroscopy. ${ }^{1} \mathbf{H}-\mathbf{N M R}$ $\left(\mathrm{CDCl}_{3}, \delta(\mathrm{ppm})\right): 1.29(\mathrm{~m}, 2 \mathrm{H}) ; 1.55(\mathrm{~m}, 2 \mathrm{H}) ; 1.57(\mathrm{t}, 2 \mathrm{H}) ; 2.18(\mathrm{t}, 2 \mathrm{H}) ; 2.61(\mathrm{t}$, $2 \mathrm{H}) ; 2.70(\mathrm{t}, 2 \mathrm{H}) ; 3.2(\mathrm{t}, 2 \mathrm{H}) ; 3.65(\mathrm{t}, 2 \mathrm{H}) ; 3.74(\mathrm{t}, 2 \mathrm{H}) ;{ }^{\mathbf{1 3}} \mathbf{C}-\mathbf{N M R}\left(\mathrm{CDCl}_{3}, \delta\right.$ $(\mathrm{ppm})): 23.5 ; 29.9 ; 30.8 ; 31.7 ; 37.26 ; 44.12 ; 49.8,72.2,174.28 ; \mathbf{I R}\left(\mathrm{KBr}, v\left(\mathrm{~cm}^{-}\right.\right.$ $\left.\left.{ }^{1}\right)\right)$ : 2918 (FF); $2864(\mathrm{~m}) ; 1656-1624$ (FF); $1463(\mathrm{f}) ; 1308$ (f); 1197 (f); 1113 (FF); 1093 (f); 725 (f).

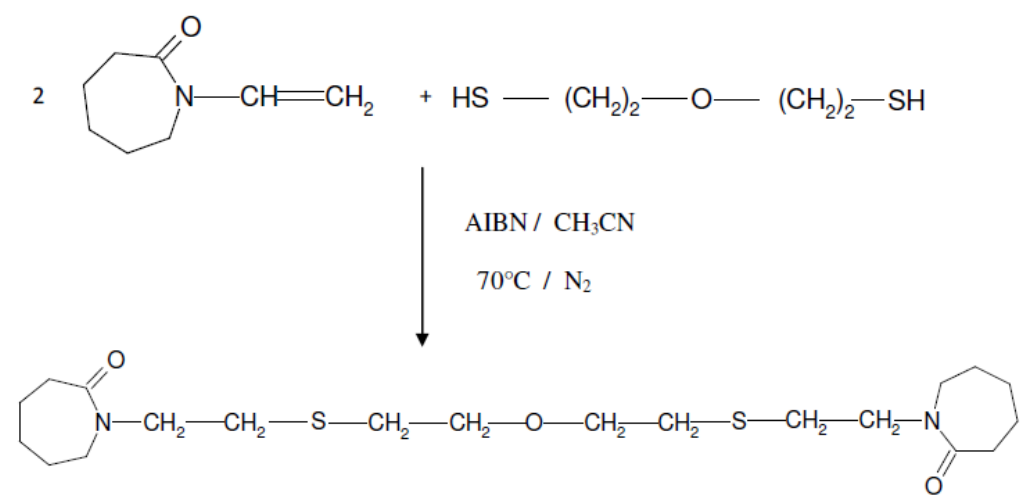

Figure 1. Structure and synthetic route of 1,1'-(2,2'-(2,2'-oxybis(ethane-2,1diyl)bis(sulfanediyl))bis(ethane-2,1-diyl))diazepan-2-one(AZEPE). 


\section{Materials}

Mild steel sheets used in this study contain $0.21 \% \mathrm{C}, 0.38 \% \mathrm{Si}, 0.05 \% \mathrm{Mn}$, $0.05 \% \mathrm{~S}, 0.09 \% \mathrm{P}, 0.01 \% \mathrm{Al}$ and the remainder iron $(\mathrm{Fe})$. The steel specimens used were pre-treated prior to the experiment by grinding with emery paper (grade 400, 600 and 1200), then rinsed with bi-distilled water, degreased, dried and immersed in the corrosive solution.

\section{Weight loss studies}

Weight loss measurements were performed at $308 \mathrm{~K}$ (except for temperature effect) for $6 \mathrm{~h}$ by immersing the mild steel specimens into non-de-aerated solution $(50 \mathrm{~mL})$ without and with various concentrations of the inhibitor. After immersion period, the steel specimens were taken out, washed, dried and weighted by an analytical balance (precision $\pm 0.1 \mathrm{mg}$ ); three experiments were performed in each case and the mean value of the weight loss is calculated.

\section{Electrochemical measurements}

Electrochemical measurements were performed in a conventional three-electrode cylindrical pyrex glass cell. The temperature is controlled at $308 \pm 1 \mathrm{~K}$. The working electrode (WE) in the form of disc is cut from steel, has a geometric area of $1 \mathrm{~cm}^{2}$ and is embedded in polytetrafluoroethylene (PTFE). A saturated calomel electrode (SCE) and a platinum electrode are used, as reference and auxiliary electrodes, respectively. The electrochemical measurements were carried out using Tacussel Radiometer PGZ 100, which was controlled by a personnel computer. Before each experiment, the work electrode was allowed to corrode freely for $1 \mathrm{~h}$ (no de-aeration, no stirring). All EIS were recorded at the open circuit potential $\mathrm{E}_{\mathrm{OCP}}$. The duration of one EIS experiment was about 20 min. The response of the electrochemical system to ac excitation with a frequency ranging mainly from $100 \mathrm{kHz}$ to $10 \mathrm{mHz}$ and peak to peak amplitude of $10 \mathrm{mV}$ was measured with data density of 10 points per decade. The impedance data were analyzed and fitted with the simulation ZView 2.8 equivalent circuit software.

The polarisation measurements were recorded after the EIS measurements on the same electrode without any further surface treatment. Before and during each experiment, the test solutions were stirred by the magnetic stirrer and de-aerated in the cell by using pure nitrogen. The polarisation curves were obtained potentiodynamically between -800 to $-200 \mathrm{mV}(\mathrm{Ag} / \mathrm{AgCl})$ with the scan rate of 1 $\mathrm{mV} \mathrm{s}^{-1}$.

\section{Results and discussions \\ Weight loss measurements}

Effect of inhibitor concentration

The effect of addition of the inhibitor tested at different concentrations on the corrosion of mild steel in $1 \mathrm{M} \mathrm{HCl}$ solution is studied by weight loss at $308 \pm 1 \mathrm{~K}$ after $6 \mathrm{~h}$ of immersion period. For every concentration of inhibitor, the mean 
value of the corrosion rate $\mathrm{W}_{\text {corr }}\left(\mathrm{mg} \mathrm{cm}^{-2} \mathrm{~h}^{-1}\right)$ was determined and the inhibitor efficiency, $\mathrm{E}_{\mathrm{W}}(\%)$, was calculated using equations (1) and (2), respectively.

$$
W_{\text {corr }}=\frac{m_{b}-m_{\mathbb{a}}}{s \times t} \quad(1) \quad E w(\%)=\left(1-\frac{W_{\text {carr }}}{W_{\text {corr }}^{*}}\right) \times 100
$$

where $m_{b}$ and $m_{a}$ are the mass of the specimen before and after immersion in the tested solution, $W_{\text {corr }}$ and $W_{\text {corr }}^{\text {a }}$ are the corrosion rates of mild steel in inhibited and uninhibited solution, respectively, $\mathrm{S}$ is the area of the mild steel specimen $\left(\mathrm{cm}^{2}\right)$ and $\mathrm{t}$ is the immersion time (h).

The results obtained are summarized in Table 1.

It is very clear that the corrosion rate $\left(\mathrm{W}_{\text {corr }}\right)$ decreases with increasing inhibitor concentration and the inhibition efficiency increases with inhibitor concentration and attains $95.56 \%$ at $1 \mathrm{mMof}$ inhibitor.

Table 1.Corrosion parameters obtained from weight loss measurements for mild steel in $1 \mathrm{M} \mathrm{HCl}$ containing various concentrations of the inhibitor at $308 \mathrm{~K}$.

\begin{tabular}{ccc}
\hline $\mathbf{C}(\mathbf{m M})$ & $\mathbf{W}_{\text {corr }}\left(\mathbf{m g ~ c m}^{-2} \mathbf{h}^{-1}\right)$ & $\mathbf{E}_{\mathbf{w}}(\boldsymbol{\%})$ \\
\hline Blanc & 2.030 & - \\
0.001 & 0.965 & 52.5 \\
0.005 & 0.428 & 78.9 \\
0.01 & 0.270 & 86.7 \\
0.05 & 0.128 & 93.7 \\
0.1 & 0.106 & 94.8 \\
0.5 & 0.104 & 94.9 \\
1 & 0.090 & 95.6 \\
\hline
\end{tabular}

Table 2. Effect of temperature on the corrosion rate of mild steel in $1 \mathrm{M} \mathrm{HCl}$ at different concentrations in the temperature range $308-353 \mathrm{~K}$ for $2 \mathrm{~h}$.

\begin{tabular}{|c|c|c|c|c|c|}
\hline $\mathbf{C}(\mathbf{m M})$ & Blank & 0.05 & 0.1 & 0.5 & 1 \\
\hline $\begin{array}{c}\text { Temperature } \\
\text { (K) }\end{array}$ & $\begin{array}{c}W_{c o r r}^{\circ} \\
\left(\mathrm{mg} \mathrm{cm}^{-2} \mathrm{~h}^{-1}\right)\end{array}$ & $\begin{array}{c}W_{\text {corr }} \\
\left(\mathrm{mg} \mathrm{cm}^{-2} \mathrm{~h}^{-1}\right) \\
(\%)\end{array}$ & $\begin{array}{c}W_{\text {corr }} \text { Ew } \\
\left(\mathrm{mg} \mathrm{cm}^{-2} \mathrm{~h}^{-1}\right) \\
(\%)\end{array}$ & $\begin{array}{c}W_{\text {corr }} \text { Ew } \\
\left(\mathrm{mg} \mathrm{cm}^{-2} \mathrm{~h}^{-1}\right) \\
(\%)\end{array}$ & $\begin{array}{cc}W_{\text {corr }} & \text { Ew } \\
\left(\mathrm{mg} \mathrm{cm}^{-2}\right. & \left.\mathrm{h}^{-1}\right) \\
(\%) & \end{array}$ \\
\hline 308 & 1.73 & 0.178 & 0.136 & 0.083 & 0.074 \\
\hline 313 & 2.43 & 89.7 & 92.1 & 95.2 & 95.7 \\
\hline 323 & 5.58 & 0.237 & 0.215 & 0.166 & 0.099 \\
\hline 333 & 12.11 & 90.2 & 91.1 & 93.1 & 95.9 \\
\hline 343 & 26.11 & 0.544 & 0.557 & 0.358 & 0.237 \\
\hline \multirow[t]{7}{*}{353} & 46.23 & 90.7 & 90.5 & 93.9 & 95.9 \\
\hline & & 1.24 & 1.11 & 0.756 & 0.560 \\
\hline & & 89.7 & 90.9 & 93.7 & 95.4 \\
\hline & & 7.12 & 3.93 & 3.63 & 2.32 \\
\hline & & 72.7 & 84.9 & 86.9 & 91.1 \\
\hline & & 28.37 & 19.19 & 7.00 & 6.22 \\
\hline & & 39.4 & 58.5 & 84.8 & 86.5 \\
\hline
\end{tabular}

\section{Effect of temperature}

The effect of temperature on the inhibition efficiency, in the temperature range 308-353 $\mathrm{K}$, in $1 \mathrm{M} \mathrm{HCl}$, was studied using gravimetric experiments in the absence and presence of $0.05,0.1,0.5$ and $1 \mathrm{mM}$ of inhibitor after $2 \mathrm{~h}$ of immersion time. The results obtained are summarized in Table 2. 
We note a slight variation in the inhibition efficiency at all concentrations for inhibitor studies in the temperature range $308-353 \mathrm{~K}$. In addition, the inhibition efficiency is quietly independent of the temperature in the range $308-333 \mathrm{~K}$.

\section{Adsorption isotherm}

It is universally accepted that the organic inhibitors act by means of physiadsorption or chemiadsorption on the metal surface. Isotherm equations are frequently used to describe the adsorption. In order to gain more information about the mode of adsorption of the inhibitor on the surface of mild steel, the experimental data have been tested with several adsorption isotherms. The values of surface coverage $(\Theta)$ for different concentrations at different temperatures have been used to explain the best isotherm that determines the adsorption process. The values of surface coverage $(\Theta)$ were evaluated from weight loss measurements by using the following equation:

$$
\theta=\frac{w_{\text {carr }}^{*}-W_{\text {corr }}}{w_{\text {corr }}}
$$

In this equation, $W_{\text {corr }}$ and $w_{\text {corr }}^{\circ}$ represent the corrosion rates of mild steel in the presence and absence of the inhibitor, respectively. The correlation of $\square$ with concentration of inhibitor was evaluated by different adsorption isotherms such as Langmuir, Frumkin and Temkin. However, the best fit was obtained from the Langmuir isotherm (Fig.2). These isotherms are given by equations (4), (5) and (6), respectively [18-20].

$$
\frac{c}{\theta}=\frac{1}{K_{a d g}}+c(4) \theta=\frac{1}{f} \ln \left(K_{a d z} \frac{c(1-\theta)}{c}\right)(5) \theta=\frac{1}{f} \ln \left(K_{a d z} C\right)
$$

where $\mathrm{K}_{\mathrm{ads}}$ is the equilibrium adsorption and $\mathrm{f}$ is the molecular interaction constant.

The equilibrium constant for adsorption process is related to the free energy of adsorption, $\Delta G_{a d s}$, and is expressed by equation (7)

$$
K_{a d z}=\frac{1}{55.55} \exp \left(-\frac{\Delta G_{a d z}}{R \times \tau}\right)
$$

where 55.55 is the molar concentration of water in the solution expressed in (mol $\left.\mathrm{I}^{-1}\right)$; $\mathrm{R}$ is the gas constant $\left(8.314 \mathrm{~J} \mathrm{~K}^{-1} \mathrm{~mol}^{-1}\right)$ and $\mathrm{T}$ is the absolute temperature (K).The heat of adsorption $\Delta H_{a d s}$ is obtained from the Van't Hoff's equation (eq. 8) [21,22]. When $L n K_{a d s}$ Vs. (1/T) is plotted (Fig. 3), the value of $\Delta H_{a a s}$ is obtained from the slope and $\Delta S_{a d s}$ is obtained for a range of temperatures with equation (9):

$$
L n K_{a d s}=-\frac{\Delta H_{a d s}}{R T}+\text { constant (8) } \quad \Delta G_{a d s}=\Delta H_{a d s}-T \Delta S_{a d s}(9)
$$

The values of $K_{a d s}, \Delta G_{a d s}, \Delta H_{a d s}$ and $\Delta S_{a d s}$ are disclosed in Table 3 . The negative values of $\Delta G_{a d s}$ along with high $K_{a d s}$ indicate a spontaneous adsorption process $[23,24]$. Generally, the $\Delta G_{a d s}$ values up to $-20 \mathrm{~kJ} \mathrm{~mol}^{-1}$ are consistent with the electrostatic interaction between the charged molecules and the charged metal (physisorption). On the other hand, negative values less than $-40 \mathrm{~kJ} \mathrm{~mol}^{-1}$ 
involve sharing or transferring of electrons from the inhibitor molecules to the metal surface to form a co-ordinate type of band (chemisorption) [25]. The calculated $\Delta G_{a d s}$ values are ranging between -41.07 and $-43.85 \mathrm{~kJ} \mathrm{~mol}^{-1}$, suggesting that the inhibitor was adsorbed chemically onto the mild steel surface. The higher values of $K_{a d s}$ and $\Delta G_{a d s}$ refer to higher adsorption and higher inhibiting effect [26]. The negative value of $\Delta H_{a d s}$ also shows that the adsorption of the inhibitor is an exothermic process [27]. The adsorption of inhibitor molecules is accompanied by negative values of $\Delta \mathrm{s}_{\mathrm{ads}}$ because of the confining of an adsorbed molecule to a thin surface layer (certain degrees of freedom are lost) [28].
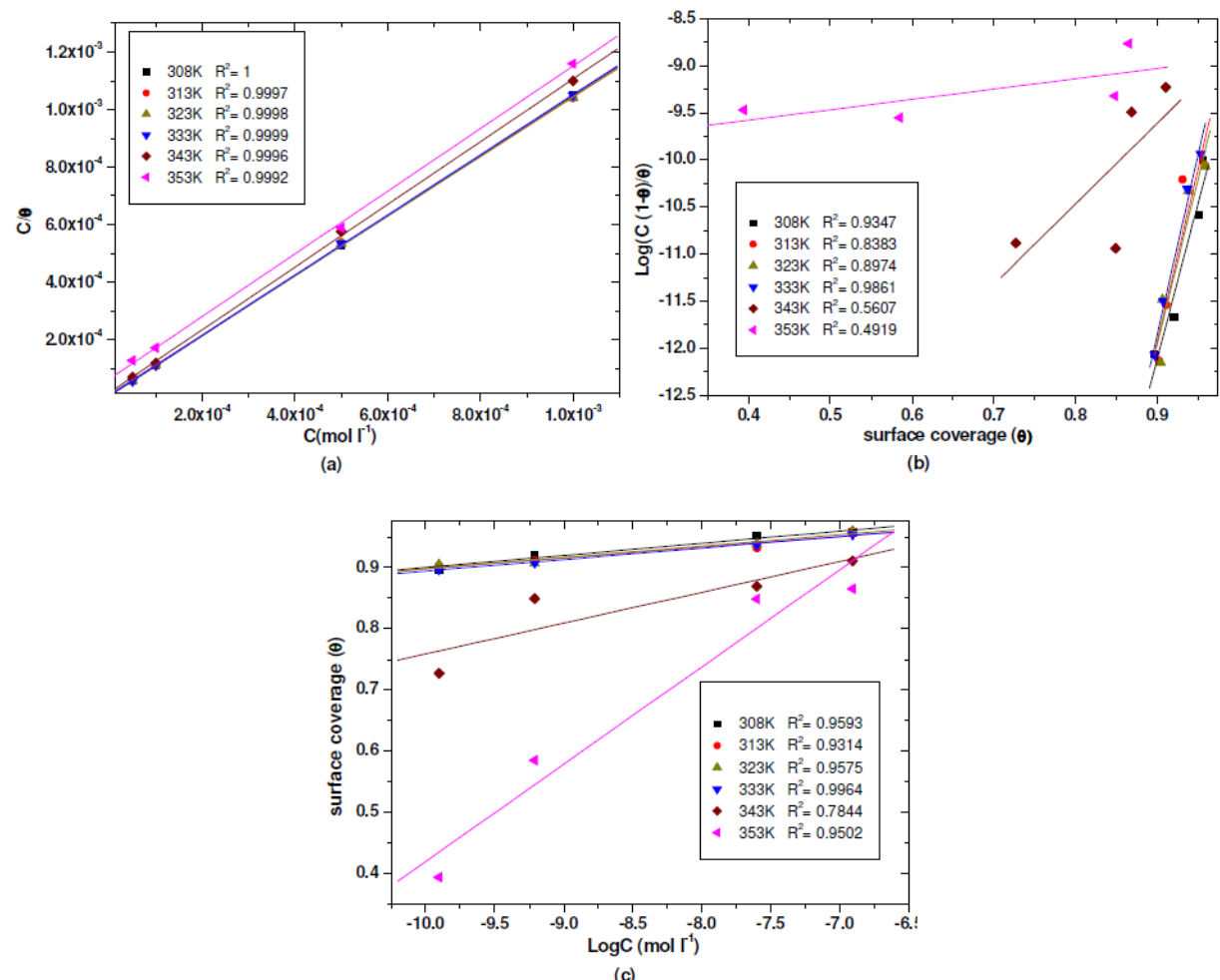

Figure 2. Different adsorption isotherm plots for the adsorption in different temperatures of the inhibitor in $1 \mathrm{M} \mathrm{HCl}$ on the surface of mild steel. (a) Langmuir's isotherm, (b) Frumkin's isotherm and (c) Temkin's isotherm.

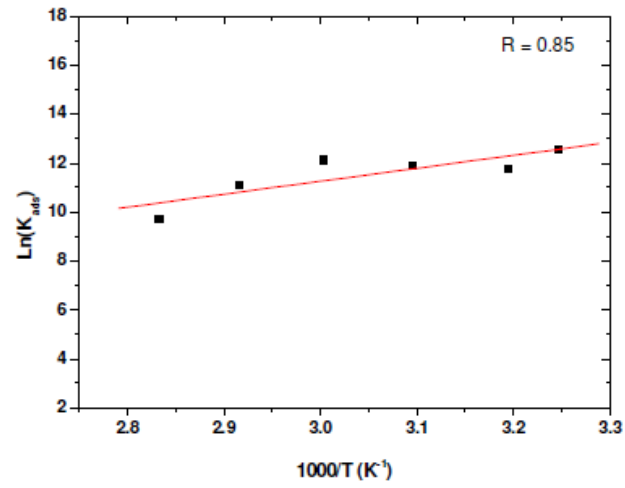

Figure 3.Vant Hoff's plot for MS in $1 \mathrm{M} \mathrm{HCl}$ in presence of the inhibitor. 
Table 3.Thermodynamic parameters for the adsorption of the inhibitor in $1 \mathrm{M} \mathrm{HCl}$ at different temperatures.

\begin{tabular}{ccccc}
\hline $\begin{array}{c}\text { Temperature } \\
(\mathbf{K})\end{array}$ & $\begin{array}{c}\mathbf{K}_{\text {ads }} \\
\left(\mathbf{M}^{\mathbf{1}}\right)\end{array}$ & $\begin{array}{c}\Delta \boldsymbol{G}_{\text {ads }} \\
\left(\mathbf{k J ~} \mathbf{~ m o l}^{\mathbf{1}}\right)\end{array}$ & $\begin{array}{c}\Delta H_{a d s} \\
\left(\mathbf{k J ~ m o l}^{\mathbf{1}}\right)\end{array}$ & $\begin{array}{c}\Delta \boldsymbol{S}_{\text {add }} \\
\left(\mathbf{J ~ K}^{-\mathbf{1}} \mathbf{~ m o l}^{\mathbf{1}}\right)\end{array}$ \\
\hline 308 & 280963.59 & -42.41 & -44.96 & -9.5 \\
313 & 129058.24 & -41.08 & & -4.66 \\
323 & 143970.65 & -42.68 & & -0.76 \\
333 & 182355.97 & -43.85 & & -3.10 \\
343 & 64650.02 & -43.04 & & -11.09 \\
353 & 15972.42 & -40.19 & & \\
\hline
\end{tabular}

\section{Activation parameters}

Kinetic model can be used to explain the inhibitor behaviour. The apparent activation energy for the corrosion process was calculated from the Arrhenius equation:

$$
\operatorname{Ln}\left(W_{\text {corr }}\right)=-\frac{E_{a}}{R \times T}+\operatorname{Ln}(A)
$$

where $E_{a}$ represents the apparent activation energy, $A$ is the pre-exponential factor and $\mathrm{W}_{\text {corr }}$ is the corrosion rate. Fig 4.a shows the Arrhenius plot of Log $\left(\mathrm{W}_{\text {corr }}\right)$ vs. $\frac{1}{T}$ in the absence and presence of different concentrations of the inhibitor at different temperatures. The enthalpy of activation $\Delta H_{a}$ and entropy of activation $\Delta S_{a}$ were obtained from the transition state equation:

$$
W_{\text {corr }}=\frac{\pi \times T}{N_{A} \times h} \exp \left(\frac{\Delta S_{a}}{R}\right) \exp \left(-\frac{\Delta H_{a}}{R \times T}\right)
$$

where $\mathrm{h}$ is the Plank's constant, $\mathrm{N}_{\mathrm{A}}$ is the Avogadro's number, $\mathrm{T}$ is the absolute temperature and $\mathrm{R}$ is the universal gas constant. Straight lines of $\log \left(\frac{W_{\text {corr }}}{T}\right)$ against $\frac{1}{T}$ are plotted in Fig. $4 \mathrm{~b} ; \Delta H_{a}$ and $\Delta S_{a}$ are obtained from the slope and intercept of the linear plots, respectively. The values Ea, $\Delta H_{a}$ and $\Delta S_{a}$ at different temperatures are presented in Table 4. We note that the linear regression coefficients are over 0.97 indicating the validation of the employed kinetic model.

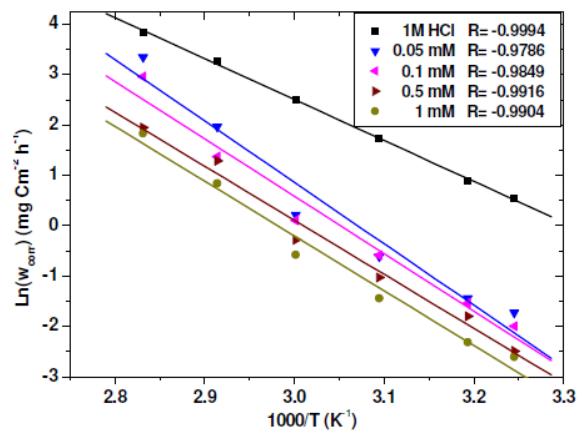

a)

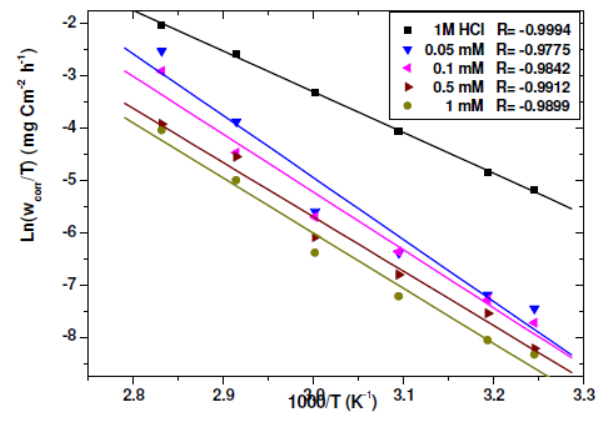

b)

Figure 4. a) Arrhenius plots for mild steel in $1 \mathrm{M} \mathrm{HCl}$ without and with different concentrations of inhibitor. b) Transition state plots for mild steel in $1 \mathrm{M} \mathrm{HCl}$ without and with different concentrations of inhibitor. 
According to the report in literature [29, 30], higher value of $\mathrm{E}_{\mathrm{a}}$ was considered as physiadsorption. Because the electrochemical corrosion is relevant to heterogeneous reaction, the pre-exponential factor $\mathrm{A}$ in the Arrhenius equation is related to the number of active centres with different $E_{a}$ on the metal surface: (i) the activation energy in the presence of the inhibitor is lower than that of pure acidic medium, namely $\mathrm{E}_{\mathrm{a}}(\mathrm{inh})<\mathrm{E}_{\mathrm{a}}(\mathrm{HCl})$, which suggests a smaller number of more active sites remaining uncovered in the corrosion process, (ii) the activation energy in the presence of the inhibitor is higher than that of pure acidic medium, $\mathrm{E}_{\mathrm{a}}$ (inh) $>\mathrm{E}_{\mathrm{a}}(\mathrm{HCl})$, which represents the inhibitor adsorbed on most active adsorption sites (having the lowest energy) and the corrosion takes place chiefly on the active sites (having the higher energy).

Table 4. Values of activation thermodynamic parameters for mild steel dissolution in 1 $\mathrm{M} \mathrm{HCl}$ in the absence and presence of different concentrations of the inhibitor.

\begin{tabular}{|c|c|c|c|c|}
\hline $\mathrm{C}(\mathrm{mM})$ & Ea $\left(\mathrm{kJ} \mathrm{mol}^{-1}\right)$ & A & $\Delta H_{a}\left(\mathrm{~kJ} \mathrm{~mol}^{-1}\right)$ & $\Delta S_{a}\left(\mathrm{~J} \mathrm{~mol}^{-1} \mathrm{~K}^{-1}\right)$ \\
\hline Blanc & 67.54 & $4.74 \times 10^{11}$ & 64.80 & -30.52 \\
\hline 0.05 & 101.26 & $1.78 \times 10^{16}$ & 98.52 & 56.99 \\
\hline 0.1 & 94.73 & $1.28 \times 10^{15}$ & 91.99 & 35.12 \\
\hline 0.5 & 89.08 & $1.03 \times 10^{14}$ & 86.34 & 14.20 \\
\hline 1 & 90.36 & $1.20 \times 10^{14}$ & 87.62 & 15.47 \\
\hline
\end{tabular}

The data in Table 4 specifically indicate that the values of $E_{a}$ in presence of the inhibitor are larger than that in the absence of the inhibitor, which is consistent with the latter mentioned above; this means that the adsorbed inhibitor molecules block the most active sites, while the sites of higher activation energy, which are greater in number, take part in the subsequent corrosion [29, 31]. The positive values of $\Delta H_{a}$ manifest the endothermic nature of the dissolution process; $\Delta S_{a}$ was also positive in the presence of the inhibitor, suggesting that active complexes were formed by the substitution of water for the inhibitor.

This part showed that physical adsorption is not neglected and the mechanism of inhibition may be endorsed that inhibition of inhibitor acted both by physical and chemical adsorption.

Inspection of the data reveals that the $\Delta H_{a}$ values for dissolution reaction of mild steel in $1 \mathrm{M} \mathrm{HCl}$ in the presence of inhibitor are higher $\left(86.34 ; 98.52 \mathrm{~kJ} \mathrm{~mol}^{-1}\right)$ than that of in the absence of inhibitor $\left(64.8 \mathrm{~kJ} \mathrm{~mol}^{-1}\right)$. The positive signs of $\Delta H_{a}$ reflect the endothermic nature of mild steel dissolution process, which suggests the slow dissolution of mild steel in presence of the inhibitor [32]. In the presence of inhibitor, one can notice the $\mathrm{E}_{\mathrm{a}}$ and $\Delta H_{a}$ values vary in the same way (Table 4). These results permit to verify the known thermodynamic relation between the Ea and $\Delta H_{a}\left(\Delta H_{a}=\mathrm{Ea}-\mathrm{T} \Delta S_{a}\right)[33,34]$.

\section{Potentiodynamic polarisation}

The values of corrosion potential $\mathrm{E}_{\text {corr }}$, corrosion current density $\mathrm{i}_{\text {corr }}$, and anodic and cathodic slopes $\left(\beta_{\mathrm{a}}\right.$ and $\left.\beta_{\mathrm{c}}\right)$ can be evaluated from anodic and cathodic regions of Tafel plots. The linear Tafel segments of anodic and cathodic curves were extrapolated to corrosion potential to obtain corrosion current densities $\left(\mathrm{i}_{\text {corr }}\right)$. 


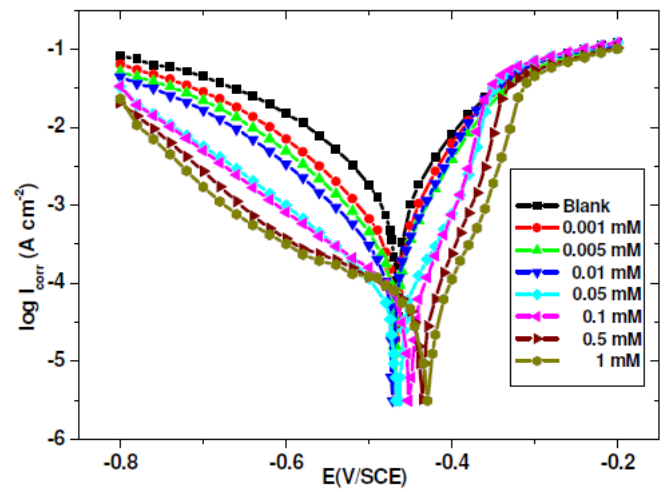

Figure 5. Potentiodynamic polarisation curves for mild steel in $1 \mathrm{M} \mathrm{HCl}$ without and with different concentrations of the inhibitor.

The inhibition efficiency was evaluated from the measured $i_{\text {corr }}$ values using the relationship

$$
E(\%)=\frac{i_{\text {corr }}^{0}-i_{\text {corr }}}{i_{\text {corr }}^{2}} \times 100
$$

where $i_{\text {corr }}$ and $i_{\text {corr }}$ are the values of corrosion current density in absence and presence of the inhibitor, respectively.

Fig. 5 shows the polarisation curves recorded on mild steel in $1 \mathrm{M} \mathrm{HCl}$ solutions in the absence and presence of different concentrations of the inhibitor. It can be seen from this figure that with the increase of inhibitor concentration, both anodic and cathodic reactions were supported through inhibitor adsorption on the mild steel surface in $1 \mathrm{M} \mathrm{HCl}$ solution.

Table 5 shows that the $i_{\text {corr }}$ decreases with the increase in inhibitor concentration and the inhibition efficiency reaches to the maximum at $1 \mathrm{mM}$ of inhibitor. From this table, it is also clear that $\mathrm{E}_{\text {corr }}$ values do not shift with inhibitor concentration. In literature, it has been reported that if the displacement in $\mathrm{E}_{\text {corr }}$ is $>85 \mathrm{mV}$ with respect to $\mathrm{E}_{\text {corr }}$, the inhibitor can be seen as of the cathodic or anodic type, and if the displacement in $\mathrm{E}_{\text {corr }}$ is $<85 \mathrm{mV}$, the inhibition can be seen as of the mixed type [35-37]. In our study the maximum displacement in $\mathrm{E}_{\text {corr }}$ value was $37 \mathrm{mV}$ towards anodic region, which indicates that the inhibitor is of the mixed type with predominance of the anodic type. The values of the slopes of the anodic Tafel lines, $\beta_{\mathrm{a}}$, are lower than those for uninhibited solution, which suggests that the inhibitor can affect the kinetics of the anodic process. The inhibition efficiencies calculated from potentiodynamic polarisation curve are in good agreement with those obtained from weight loss measurements.

\section{Electrochemical impedance spectroscopy (EIS) measurements}

The corrosion behaviour of MS in $1 \mathrm{M} \mathrm{HCl}$ solution in the absence and presence of various concentrations of the inhibitor after immersion for $1 \mathrm{~h}$ at $308 \mathrm{~K}$ was investigated using EIS. In general, kinetic information of the electrode interface between the mild steel and the test solution can be obtained from the shape of the impedance diagrams [38]. The recorded EIS spectrum for $\mathrm{MS}$ in $1 \mathrm{M} \mathrm{HCl}$ solution in absence and presence of different concentrations (except 0.5 and 1 $\mathrm{mM}$ ) (Fig.6) shows a depressed capacitive loop in the high frequency (HF) range and an inductive loop in the lower frequency (LF) range. The HF capacitive loop 
can be attributed to the charge transfer reaction and time constant of the electric double layer and to the surface non-homogeneity of interfacial origin, such as those found in adsorption process on metal surface, and the LF inductive loop may be attributed to the relaxation process like $\mathrm{Cl}_{\text {ads }}^{-}$and $\mathrm{H}^{+}$ads on working electrode surface [39]. For the concentration 0.5 and $1 \mathrm{mM}$, Fig.6 shows only one depressed capacitive loop.

Table 5. Polarisation parameters and the corresponding inhibition efficiency for corrosion of mild steel in $1 \mathrm{M} \mathrm{HCl}$ solution containing different concentrations of inhibitor.

\begin{tabular}{|c|c|c|c|c|c|}
\hline $\begin{array}{c}\mathrm{C} \\
(\mathrm{mM})\end{array}$ & $\begin{array}{l}\mathbf{E}_{\text {corr }} \\
(\mathbf{m V})\end{array}$ & 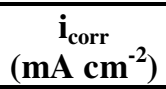 & $\begin{array}{c}\boldsymbol{\beta}_{\mathrm{a}} \\
\left(\mathbf{m V} \operatorname{dec}^{-1}\right)\end{array}$ & $\begin{array}{c}\beta c \\
\left(\mathrm{mV} \operatorname{dec}^{-1}\right)\end{array}$ & $\begin{array}{c}\mathrm{E}_{\mathrm{i}} \\
(\%)\end{array}$ \\
\hline Blanc & -467.3 & 0.966 & 71.1 & -101 & - \\
\hline 0.001 & -469.8 & 0.372 & 55.5 & -98.1 & 61.5 \\
\hline 0.005 & -470.0 & 0.224 & 55.2 & -90.6 & 76.8 \\
\hline 0.01 & -473.6 & 0.213 & 52.8 & -104.7 & 77.9 \\
\hline 0.05 & -467.4 & 0.047 & 55.9 & -93.7 & 95.1 \\
\hline 0.1 & -452.7 & 0.036 & 38.9 & -90.6 & 96.2 \\
\hline 0.5 & -437.2 & 0.035 & 41.4 & -135.1 & 96.3 \\
\hline 1 & -430.0 & 0.030 & 47.8 & -130.6 & 96.9 \\
\hline
\end{tabular}

The diameters of capacitive loops increase with the increase in inhibitor concentration, which indicates the increase of charge transfer and improvement in inhibiting effect on MS corrosion (Fig.6). It reveals that the presence of the inhibitor in $1 \mathrm{M} \mathrm{HCl}$ solutions increases the charge transfer resistance due to the formation of a protection layer on the MS surface, but it does not change other aspects of the corrosion behaviour. These results agree with those of polarization measurements, that is, the inhibitor does not substantially alter the electrochemical reactions mechanism. The above observation is also verified by the Bode plots (Fig. 6). Each Bode-phase diagram consists of a single wave crest and a portion of curve under the zero phase degree. However, it is clear that the shapes of the impedance plots for the inhibited electrodes are not essentially different from those of the uninhibited electrodes. Electrical equivalent circuits are generally used to model the electrochemical behaviour and to calculate the impedance parameters [40].
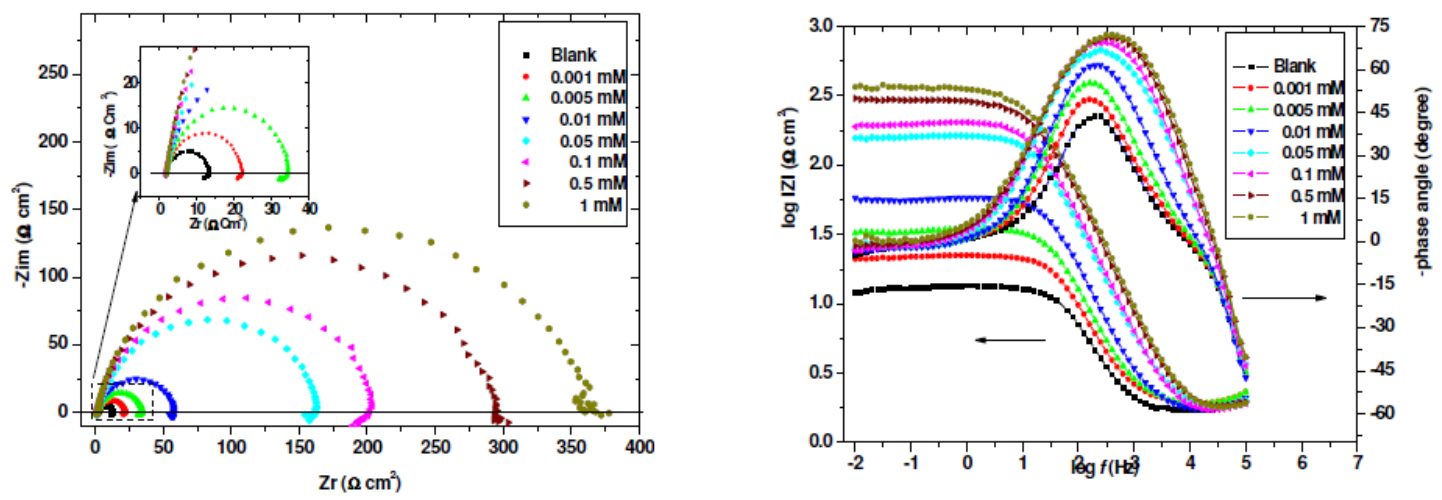

Figure 6. Nyquist and Bode-phase diagrams for mild steel in $1 \mathrm{M} \mathrm{HCl}$ containing different concentrations of inhibitor at $308 \mathrm{~K}$. 


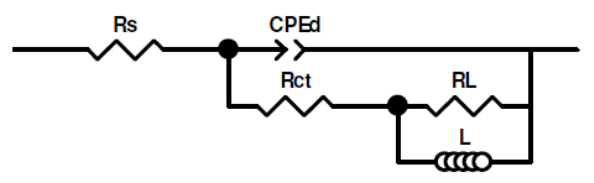

(a)

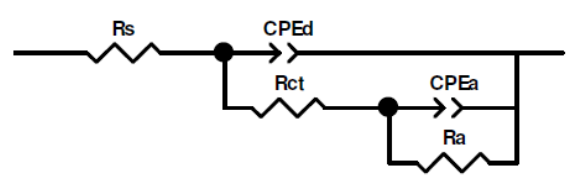

(b)

Figure 7. Electrical equivalent circuit used for modelling the interface mild steel / $1 \mathrm{M}$ $\mathrm{HCl}$ solution without and with inhibitor.

Figs.7a \& b show the equivalent circuit model used to fit the experimental impedance data of $\mathrm{MS}$ in $1 \mathrm{M} \mathrm{HCl}$ in absence and presence of different concentrations (except 0.5 and $1 \mathrm{mM}$ ). In this case the addition of inhibitor has no effect on the shape of the impedance spectra; two equivalent circuits may be proposed to fit these systems that charge transfer controls the corrosion process. The same equivalent circuit was often used to describe the corrosion inhibition caused by organic compounds in acidic medium [41-46].

In the equivalent circuit $R_{s}$ is the solution resistance, $C_{d}$ is a constant phase element, $R_{c t}$ is the charge transfer resistance, $L$ is the inductance and $R_{c t}+R_{L}$ presents the polarisation resistance $\left(\mathrm{R}_{\mathrm{P}}\right)$. Resistance $\mathrm{R}_{\mathrm{L}}$ and inductance $\mathrm{L}$ may be correlated with a slow frequency intermediate process [47]. The presence of inductance $\mathrm{L}$ in the impedance spectra indicates that the MS is still dissolved by the direct charge transfer in the presence of the inhibitor [45]. The constant phase element, $\mathrm{CPE}$, is introduced in the circuit instead of a pure double layer capacitor in order to take into account the electrode surface heterogeneity resulting from surface roughness, impurities, dislocations, grain boundaries, adsorption of inhibitors, formation of porous layers [31,48] and therefore to give a more accurate fit [49]. The impedance of the $\mathrm{CPE}$ is expressed as:

$$
Z_{C P E}=\frac{2}{A\left[(h)^{n}\right)^{n}}
$$

where $A$ is the proportionality of CPE (in $\Omega^{-1} \mathrm{~s}^{\mathrm{n}} \mathrm{cm}^{-2}$ ), $\omega$ is the sine wave modulation angular frequency (in $\operatorname{rad~s}^{-1}$ ), $i^{2}=-1$ is the imaginary number, and $n$ is an empirical exponent which measures the deviation from the ideal capacitive behaviour [50,51]. The CPE can be expressed by the values of $\mathrm{n}$ if resistance $(\mathrm{n}=$ $0, A=R)$, capacitance $(n=1, A=C)$, Inductance $(n=-1, A=L)$ and Warburg impedance $(\mathrm{n}=0.5, \mathrm{~A}=\mathrm{W})$ [52]. The experimental data were very well fitted according to the proposed equivalent circuit and as an example; the simulated curves are presented in Fig. 8. The corresponding fitting results are listed in Table 6. In this table are also shown the calculated double layer capacitance $\left(C_{\mathrm{dl}}\right)$ derived from the $\mathrm{CPE}_{\mathrm{d}}$ parameters according to equation (14) [53]; the relaxation time constant $\left(\tau_{\mathrm{d}}\right)$ of charge-transfer process was calculated using equation (15) [53]:

$$
C_{d l}=\left(A_{d}\left(R_{c t}\right)^{1-n_{d}}\right)^{1 / n_{d i}}(14) \quad \tau_{d}=C_{d l} \times R_{c t}
$$



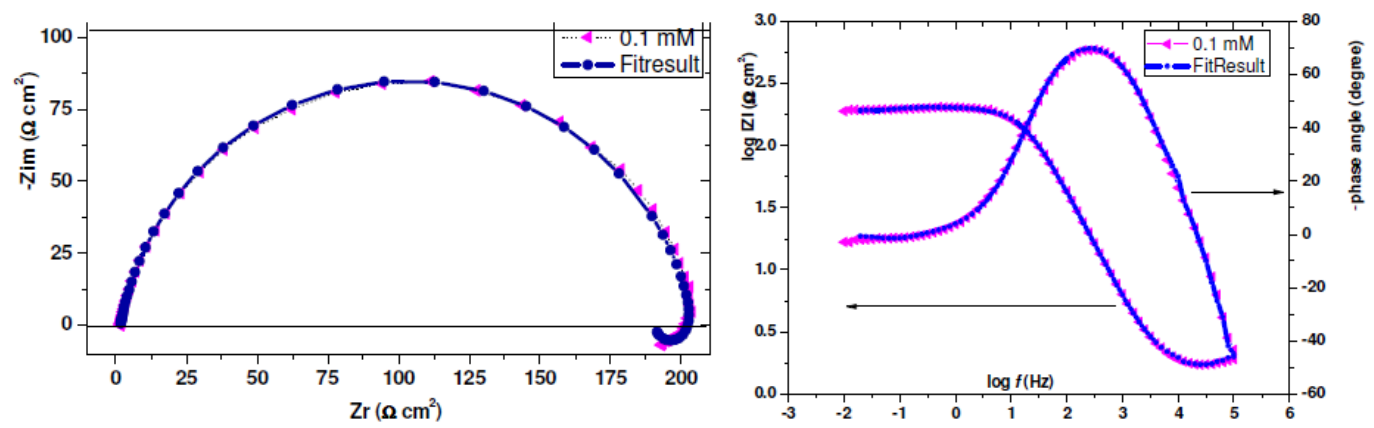

Figure 8. EIS Nyquist and Bode-phase diagram for mild steel / $1 \mathrm{M} \mathrm{HCl}+0.1 \mathrm{mM}$ of inhibitor interface using structural model in Fig. 7a.

Results in Table 6 show that $R_{c t}$ value increased with the concentration of the inhibitor. In addition, the value of proportional factor $\mathrm{A}$ of $\mathrm{CPE}$ varies in a regular manner with inhibitor concentration. The change in the values of $R_{c t}$ and A can be related to the gradual removal of water molecules by AZEPE molecules on the electrode surface and consequently leads to decrease in the number of active sites necessary for the corrosion reaction [54].

The value of the relaxation time constant $\left(\tau_{\mathrm{d}}\right)$ slowly increases with AZEPE concentration as well and the time of adsorption process becomes therefore much higher, which means a slow adsorption process [55]. This shows that there is an agreement between the amount of charge that can be stored (that is capacitance) and discharge velocity in the interface $\left(\tau_{\mathrm{d}}\right)$ [56]. At LF region, the inductance (L) increases with inhibitor concentration.

Table 6.Impedance parameters and inhibition efficiency values for mild steel after $1 \mathrm{~h}$ immersion period in $1 \mathrm{M} \mathrm{HCl}$ containing different concentrations of AZEPE at $308 \mathrm{~K}$.

\begin{tabular}{|c|c|c|c|c|c|c|c|c|}
\hline $\begin{array}{c}\mathbf{C} \\
(\mathbf{m M})\end{array}$ & $\begin{array}{c}\mathbf{R}_{\mathrm{s}} \\
\left(\boldsymbol{\Omega} \mathrm{cm}^{2}\right)\end{array}$ & $\begin{array}{c}10^{6} \mathbf{A}_{d} \\
\left(\Omega^{-1} s^{n} c^{-2}\right)\end{array}$ & $\mathbf{n}_{\mathrm{d}}$ & $\begin{array}{c}\mathbf{R}_{\mathrm{ct}} \\
\left(\Omega \mathrm{cm}^{2}\right)\end{array}$ & $\begin{array}{c}\mathbf{C}_{\mathrm{dl}} \\
(\mu \mathrm{F} \mathrm{cm})\end{array}$ & $\begin{array}{c}\boldsymbol{\tau}_{\mathrm{d}} \\
(\mathrm{ms})\end{array}$ & \multicolumn{2}{|c|}{$\begin{array}{c}\mathbf{R}_{\mathbf{L}} \\
\left(\boldsymbol{\Omega} \mathrm{cm}^{2}\right)\end{array}$} \\
\hline Blanc & 1.705 & 385.69 & 0.906 & 10.03 & 217.34 & 2.18 & 1.63 & \\
\hline 0.001 & 1.954 & 306.04 & 0.895 & 18.8 & 167.10 & 3.14 & 1.69 & \\
\hline 0.005 & 1.939 & 237.67 & 0.895 & 30.21 & 133.21 & 4.02 & 3.04 & \\
\hline 0.01 & 1.781 & 153.24 & 0.897 & 52.81 & 88.14 & 4.65 & 4.53 & \\
\hline 0.05 & 1.805 & 94.39 & 0.867 & 155.7 & 49.40 & 7.69 & 9.78 & \\
\hline 0.1 & 1.695 & 74.54 & 0.886 & 189.2 & 43.08 & 8.15 & 13.80 & \\
\hline 0.5 & 1.892 & 40.51 & 0.917 & 181.6 & 25.97 & 4.72 & - & \\
\hline 1 & 1.885 & 34.78 & 0.919 & 200.2 & 22.45 & 4.49 & - & \\
\hline $\begin{array}{c}\mathbf{C} \\
(\mathbf{m M})\end{array}$ & $\begin{array}{c}\mathrm{L} \\
\left(\mathrm{H} \mathrm{cm}^{-2}\right)\end{array}$ & $\begin{array}{c}10^{6} \mathbf{A}_{\mathrm{a}} \\
\left(\Omega^{-1} \mathrm{~s}^{\mathbf{n}} \mathrm{cm}^{-2}\right)\end{array}$ & $\mathbf{n}_{\mathrm{a}}$ & $\begin{array}{c}R_{\mathrm{a}} \\
\left(\Omega \mathrm{cm}^{2}\right)\end{array}$ & 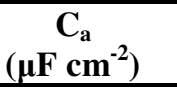 & $\begin{array}{c}\tau_{\mathrm{a}} \\
(\mathrm{ms})\end{array}$ & $\begin{array}{c}\mathbf{R}_{\mathbf{p}} \\
\left(\mathbf{\Omega} \mathbf{c m}^{2}\right)\end{array}$ & $\begin{array}{l}\mathbf{E}_{\mathbf{Z}} \\
(\%)\end{array}$ \\
\hline Blanc & 12.72 & - & - & - & - & - & 11.74 & - \\
\hline 0.001 & 4.38 & - & - & - & - & - & 20.75 & 43.5 \\
\hline 0.005 & 2.31 & - & - & - & - & - & 32.15 & 63.5 \\
\hline 0.01 & 3.50 & - & - & - & - & - & 54.59 & 78.5 \\
\hline 0.05 & 7.20 & - & - & - & - & - & 157.51 & 92.6 \\
\hline 0.1 & 22.72 & - & - & - & - & - & 190.90 & 93.8 \\
\hline 0.5 & - & 209.14 & 0.705 & 112.17 & 43.50 & 4.88 & 295.66 & 96.0 \\
\hline 1 & - & 209.84 & 0.671 & 163.3 & 40.19 & 6.56 & 365.39 & 96.8 \\
\hline
\end{tabular}

The related inhibition efficiency, $\mathrm{E}_{\mathrm{Z}}(\%)$, is calculated from $R_{P}=\left(R_{\mathrm{ct}}+R_{\mathrm{L}}\right)$ using the following equation (16): 


$$
E_{Z}(\%)=\frac{E_{p}-R_{p}^{\circ}}{R_{p}^{*}}(16)
$$

where $R_{p}^{0}$ and $R_{p}$ are the ac polarisation resistance of mild steel electrode in the uninhibited and inhibited solutions, respectively.

The equivalent circuit for the concentrations 0.5 and $1 \mathrm{mM}$ of inhibitor is shown in Fig 7.b. In this model $R_{\mathrm{s}}$ refers the solution resistance, $R_{\mathrm{ct}}$ the charge transfer resistance, $\mathrm{CPE}_{\mathrm{d}}$ the constant phase element of the high frequency semicircle that can be attributed to the charge transfer process, $R_{a}$ the resistance of the adsorbed inhibitor, $\mathrm{CPE}_{\mathrm{a}}$ the constant phase element of the inhibitor film due to the inhibitor's adsorption on the steel surface, and the sum $R_{c t}+R_{a}$ presents the polarisation resistance $R_{P}$. The same equivalent circuit was often used to describe the corrosion inhibition caused by organic compounds in acidic medium [1, 53,57-58]. The time constant of the adsorption process is $\tau_{a}=R_{a} C_{a}$, the adsorption capacitance being again replaced by a CPE, and $C_{\mathrm{a}}$ is calculated by equation (17).

$$
C_{a}=\left(A_{a}\left(R_{a}\right)^{1-n_{a}}\right)^{1 / n_{a}}
$$

The experimental data were very well fitted according to the proposed equivalent circuit and as an example; the calculated curves are presented in Fig. 9. The main fitted parameters are summarised in Table 6 . From these results, it's clear that $R_{\mathrm{ct}}$ increase and $C_{\mathrm{dl}}$ decrease with inhibitor concentration. A large $R_{\mathrm{ct}}$ is associated with a slower corroding system $[48,59]$. Furthermore, the decrease in the $C_{\mathrm{dl}}$ with increase in inhibitor concentrations may be attributed to the formation of a protective layer on the mild steel surface [60]. The increase of the $n_{d}$ values after addition of AZEPE in $1 \mathrm{M} \mathrm{HCl}$ solution (0.917-0.919) when compared to that obtained in uninhibited solution (0.889) can be explained by some decrease of the initial surface heterogeneity, due to the adsorption of the inhibitor on the most active adsorption sites on the steel surface[48]. In the same way, the values of the adsorption time constant $\tau_{\mathrm{a}}$ show a marked tendency to increase with concentration and they are higher than $\tau_{\mathrm{d}}$; the apparent increase of $\tau_{\mathrm{a}}$ with concentration is influenced by the adsorption process. The values of $n_{a}$ are lower than those of $n_{d}$, indicating greater energy distribution in the adsorption layer [53]. The resistance values $R_{a}$ are lower than $R_{c t}$ values, so the total resistance $R_{P}$ is dominated by $R_{c t}$ and increases significantly with the inhibitor concentration.
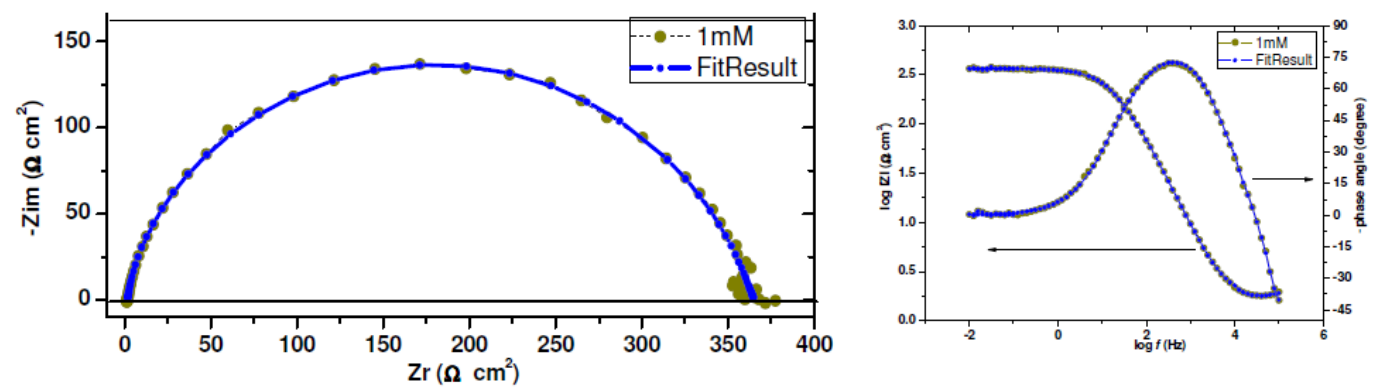

Figure 9. EIS Nyquist and Bode-phase diagram for mild steel / $1 \mathrm{M} \mathrm{HCl}+1 \mathrm{mM}$ of inhibitor interface using structural model in Fig. 7b. 
The related inhibition efficiency, $\mathrm{E}_{\mathrm{Z}}(\%)$, is calculated from $R_{P}=\left(R_{\mathrm{ct}}+R_{\mathrm{a}}\right)$ using eq (16). It is obvious that the increase in inhibitor concentration enhances $R_{P}$, and consequently improves the inhibition efficiency till reaching their maximum value at $1 \mathrm{mM}\left(\mathrm{R}_{\mathrm{P}}=365.39 \Omega \mathrm{cm}^{2}, \mathrm{E}_{\mathrm{Z}}(\%)=96.76\right)$ The inhibition efficiency calculated by EIS shows the same trend as those obtained from the weight loss measurements and the potentiodynamic polarisation methods.

\section{Conclusions}

The principal findings of the present work can be summarised as follows:

The compound 1,1'-(2,2'-(2,2'-oxybis(ethane-2,1-diyl)bis(sulfanediyl))bis(ethane2,1-diyl))diazepan-2-one, is a good inhibitor for steel in $1 \mathrm{M} \mathrm{HCl}$.

The adsorption of the inhibitor obeys the Langmuir adsorption isotherm. The high value of adsorption equilibrium constant and negative value of free energy of adsorption suggested that the inhibitor is strongly adsorbed on MS surface.

The temperature effect reveals that the AZEPEis a good inhibitor at high temperature.

The polarisation measurements reveal that AZEPEbehaves as a mixed type inhibitor by inhibiting both anodic metal dissolution and cathodic hydrogen evolution reactions.

Data obtained from electrochemical impedance spectroscopy (EIS) technique show an increase of the polarisation resistance $\left(R_{P}\right)$ and a decrease of the capacitance values with the concentration of the inhibitor. Both double layer and adsorption capacitances are distributed and therefore modelled by constant phase elements (CPE) due to the surface inhomogeneity.

Values of the corrosion inhibition efficiency, determined by weight loss, potentiodynamic polarisation and EIS measurements are in reasonable agreement.

\section{References}

1. Doner A, GulfezaKardas. Corros Sci 2011;53:4223.

2. Bentiss F, Traisnel M, Lagrenee M. Corros Sci. 2000;42:127.

3. Pillali C, Narayan R.Corros Sci. 1983;23:151.

4. Growcock F, Lopp VR, Corros Sci. 1988;28:397.

5. Bekkouch K, Aouniti A, Hammouti B, et al. J Chim Phys. 1999;96:838.

6. $\quad$ Kertit S, Bekkouche K, Hammouti B, Rev Métall. 1998;95: 251.

7. Bouzidi D, Kertit S, Hammouti B, et al. J ElectrochemSoc India 1997;46:23.

8. Kertit S, Hammouti B, Taleb M, et al. Bull Electrochem. 1997;13:241.

9. Hammouti B, Melhaoui A, Kertit S. Bull Electrochem. 1997;13:97.

10. Touhami F, Aouniti A, Kertit S, et al. Corros Sci. 2000;42:929.

11. Touhami F, Hammouti B, Aouniti A. Ann Chim Sci Mat. 1999;24:581.

12. Aouniti A, Hammouti B, Brighli M, et al. J Chim Phys. 1996;93:1262.

13. Hammouti B, Aouniti A, Taleb M, et al. Corrosion. 1995;51:411.

14. Aouniti A, Hammouti B, Kertit S. Bull Electrochem. 1998;14:193. 
15. Avci G. Mater Chem Phys. 2008;112:234.

16. Avci G. Colloids Surf A: Physicochem Eng Asp. 2008;317:730.

17. Doner A, Solmaz R, Ozcan M, et al. Corros Sci. 2011;53:2902.

18. Bayol E, Kayakırılmaz K, Erbil M. Mater Chem Phys. 2007;104:74.

19. Frumkin AN. Prog. Surf Sci. 1977;8:1.

20. Durnie W, Marco RD, Jefferson A, et al. J Electrochem Soc. 1999;146:1751.

21. Zhao TP, GN Um. Corros Sci. 1999;41:1937.

22. Tang L, Mu G, Liu G. Corros Sci. 2003;45:2252.

23. Scendo M. Corros Sci. 2007;49:373.

24. Soltani N, Behpour M, Ghoreishi SM, et al. Corros Sci. 2010;52:1351.

25. Bouklah M, Hammouti B, Lagrenee M, et al. Corros Sci. 2006;48:2831.

26. Solmaz R, G Kardas, Culha M, et al. Electrochim Acta. 2008;53:5941.

27. Gomma MK, Wahdan MH. Mater Chem Phys. 1995;39:209.

28. Do DD. Adsorption Analysis: Equilibria \& Kinetics. London: Imperial College Press; 1998.

29. Chen W, Luo HQ, Li NB. Corros Sci. 2011;53: 3356.

30. Tu S, Jiang X, Zhou L, et al. Corr Sci. 2012;65:13.

31. Popova A, Sokolova E, Raicheva S. et al. Corros Sci. 2003;45:33.

32. Guan NM, Xueming L, Fei L. Mater Chem Phys. 2004;86:59.

33. Ahamad I, Prasad R, Quraishi MA. Corros Sci. 2010;52:933.

34. Yadav DK, Quraishi MA, Maiti B. Corros Sci. 2012;55:254.

35. Ashassi-Sorkhabi H, Majidi MR, Seyyedi K. Appl Surf Sci. 2004;225:176.

36. Riggs Jr OL. Corrosion Inhibitors. 2nd ed. Houston, TX;1973.

37. Behpour M, Ghoreishi SM, Mohammadi N, et al. Corros Sci. 2010;52:4046.

38. Lorenz WJ, Mansfeld F. Corros Sci 1981;21: 647.

39. Ahamad I, Prasad R, Quraishi MA. Corros Sci. 2010;52: 933.

40. Macdonald JR. Electroanal Chem. 1987;223: 25.

41. Khaled KF, Amin MA. Corros Sci. 51 2009; 1964.

42. Amin MA, Ibrahim MM. Corros Sci. 53 2011; 873.

43. Hermas AA, Morad MS, Wahdan MH. Appl Electrochem. 2004;34:95.

44. Poornima T, Jagannatha N, Shetty AN. Port Electrochim Acta. 2010;28:173.

45. Zarrok H, Zarrouk A, Hammouti B, et al. Corros Sci. 2012;64:243.

46. Chen W, Luo HQ, Li NB. Corros Sci. 2011; 53:3356.

47. Gojic M. Corros Sci. 2001;43:919.

48. Growcock FB, Jasinski JH. J Electrochem Soc. 1989;136:2310.

49. Macdonald JR, Johanson WB. In: JR Macdonald (Ed.). Theory in impedance spectroscopy. New York:John Wiley\& Sons;1987.

50. Lopez DA, Simison SN, de Sanchez SR. Electrochim Acta. 2003;48:845.

51. Stoynov ZB, Grafov BM, Savova-Stoynova B, et al. Electrochemical Impedance. Moscow:Nauka;1991.

52. Singh AK, Quraishi MA. Corros Sci 2010;52:1373.

53. Popova A, Christov M, Vasilev A. Corros Sci. 2007;49:3290. 
54. Bentiss F, Lebrini M, Lagrenee M, et al. Electrochim Acta. 2007;52:6865.

55. Popova A, Christov M, Vasilev A. Corros Sci. 2011;53:1770.

56. Khaled KF, Al-Qahtani MM. Mater Chem Phys. 2009;113:150.

57. Bentiss F, Outirite $\mathrm{M}$, Traisnel $\mathrm{M}$, et al. Int $\mathrm{J}$ Electrochem Sci. 2012;7:1699.

58. Yuce AO, Kardas G. Corros Sci. 2012;58:86.

59. Lebrini M, Bentiss F, Chihib N, et al. Corros Sci. 2008;50:2914.

60. Kedam M, Mattos OR, Takenouti H. J Electrochem Soc. 1981;128:266. 